LLC, Shawn Rose Employee of: Janssen Research \& Development, LLC, Frederic Baribaud Shareholder of: Janssen Research \& Development, LLC, Employee of: Janssen Research \& Development, LLC, Jarrat Jordan Employee of: Janssen Research \& Development, LLC DOI: 10.1136/annrheumdis-2020-eular.2407

\section{OP0162 ABATACEPT TREATMENT FOR PATIENTS WITH EARLY ACTIVE PRIMARY SJÖGREN'S SYNDROME: OPEN-LABEL EXTENSION PHASE OF A RANDOMIZED CONTROLLED PHASE III TRIAL}

S. Arends ${ }^{1}$, J. F. Van Nimwegen ${ }^{1}$, E. Mossel ${ }^{1}$, G. S. Van Zuiden ${ }^{1}$, K. Delli ${ }^{2}$, A J. Stel ${ }^{1}$, B. Van der Vegt ${ }^{3}$, E. A. Haacke ${ }^{3}$, L. Olie ${ }^{4}$, L. Los ${ }^{4}$, G. M. Verstappen ${ }^{1}$ S. A. Pringle ${ }^{1}$, F. K. L. Spijkervet ${ }^{2}$, F. G. M. Kroese ${ }^{1}$, A. Vissink ${ }^{2}$, H. Bootsma ${ }^{1}$. ${ }^{1}$ University Medical Center Groningen, Rheumatology and Clinical Immunology, Groningen, Netherlands; ${ }^{2}$ University Medical Center Groningen, Oral and Maxillofacial Surgery, Groningen, Netherlands; ${ }^{3}$ University Medical Center Groningen, Pathology and Medical Biology, Groningen, Netherlands; ${ }^{4}$ University Medical Center Groningen, Ophthalmology, Groningen, Netherlands

Background: Abatacept (CTLA-4-lg) targets the CD80/CD86:CD28 co-stimulatory pathway required for full T-cell activation and T-cell dependent activation of B-cells. The Abatacept Sjögren Active Patients phase III (ASAPIII) trial is a mono-center, investigator-initiated, placebo controlled study with an open-label extension phase (NCT02067910), which assessed the efficacy and safety of weekly subcutaneous abatacept $(125 \mathrm{mg})$ in patients with early active primary Sjögren's syndrome (pSS). Previous analyses of the double blind phase showed no significant effect of abatacept treatment compared to placebo on the primary endpoint, difference in EULAR Sjögren's syndrome disease activity index (ESSDAl) at week $24{ }^{1}$

Objectives: To evaluate the efficacy and safety of extended (48 weeks) open label abatacept treatment in pSS patients.

Methods: Included patients had biopsy-proven pSS, fulfilled the AECG and ACR-EULAR criteria, had disease duration $\leq 7$ years (median 2 years), ESSDAI $\geq 5$, and $89 \%$ were anti-SSA positive. All 40 patients who received abatacept (ABA) in week 0-24 were subsequently treated with abatacept from week 24-48. Of the 40 patients who received placebo (PLB) in week 0-24, 2 were lost to follow up, and 38 were treated with abatacept from week 24-48. Systemic disease activity (ESSDAI), patient reported symptoms (ESSPRI), serological outcomes ( $R F$ and $\lg G$ ), ocular staining score (OSS) and unstimulated whole salivary flow (UWS) were assessed. We evaluated whether outcomes improved within treatment groups, from week 0 to subsequent visits and from week 24 to subsequent visits:

1. Within $A B A \rightarrow A B A$ treated patients:

a. Week $0-48$ to assess overall efficacy.

b. Week 24-48 to assess additional efficacy of long term treatment.

2. Within PLB $\rightarrow A B A$ treated patients:

a. Week 0-24 to assess whether a placebo effect occurred.

b. Week 24-48 to assess short-term efficacy of open label ABA.

GEE modeling was used to test significance of changes over time. Missing data were not imputed.

Results: ESSDAl and ESSPRI were improved within ABA/ABA patients between week 0-48 with additional efficacy after week 24, and within PLB/ABA patients after switching to ABA. Significant decreases in ESSDAI and ESSPRI were also seen within PLB treated patients between week 0-24 (Figure 1). IgG and RF were improved within ABA/ABA patients between week 0-48 with additional efficacy after week 24, and within PLB/ABA patients after switching to ABA. OSS was improved within $A B A / A B A$ treated patients between week 0-48. UWS only showed significant improvement in week 36 within ABA/ABA treated patients. No changes in IgG, RF, OSS or UWS were seen within PLB treated patients. No deaths occurred. One serious adverse event possibly related to intervention occurred during ABA treatment.

Conclusion: ESSDAI and ESSPRI improved significantly during 48-week treatment with abatacept. Placebo treated patients also showed significant improvement in both indices and further improvement occurred after switching to abatacept. Biological activity was decreased by abatacept treatment. 48-week abatacept treatment improved OSS, and might improve UWS. Abatacept was well tolerated by pSS patients.

References:

[1] van Nimwegen et al. Lancet Rheumatol. Published online 31-01-2020

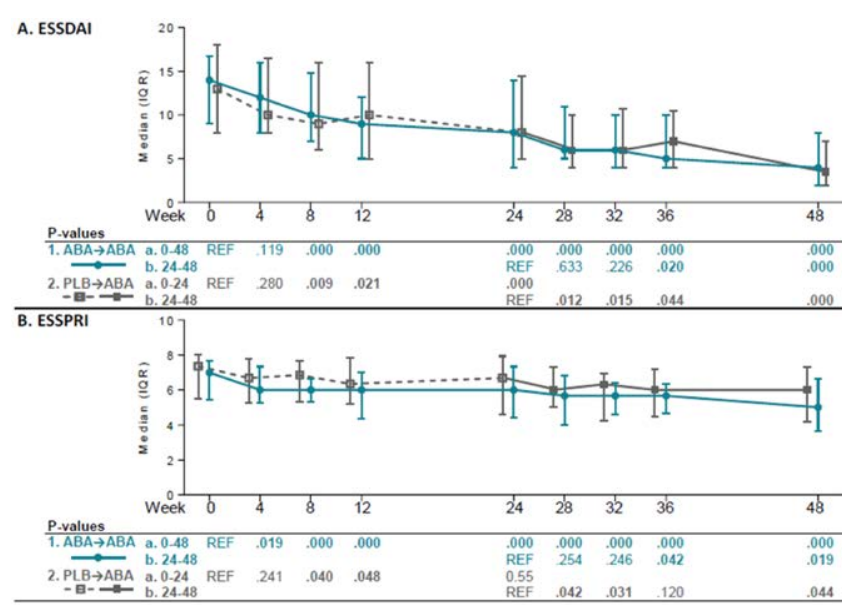

Figure 1. ESSDAI (A) and ESSPRI (B) during ABA/ABA treatment and PLB/ABA treatment in pSS

Acknowledgments: This study was funded by Bristol-Myers Squibb. We thank all patients for participation in the ASAP-III trial.

Disclosure of Interests: Suzanne Arends Grant/research support from: Grant/ research support from Pfizer, Jolien F. van Nimwegen Consultant of: Bristol-Myers Squibb, Speakers bureau: Bristol-Myers Squibb, Esther Mossel: None declared, Greetje S. van Zuiden Speakers bureau: Roche, Konstantina Delli: None declared, Alja J. Stel: None declared, Bert van der Vegt Consultant of: Advisory board member for Philips and Visiopharm., Erlin A. Haacke: None declared Lisette Olie: None declared, Leoni Los: None declared, Gwenny M. Verstappen: None declared, Sarah A. Pringle: None declared, Fred K.L. Spijkervet: None declared, Frans G.M. Kroese Grant/research support from: Unrestricted gran from Bristol-Myers Squibb, Consultant of: Consultant for Bristol-Myers Squibb, Speakers bureau: Speaker for Bristol-Myers Squibb, Roche and Janssen-Cilag, Arjan Vissink: None declared, Hendrika Bootsma Grant/research support from: Unrestricted grants from Bristol-Myers Squibb and Roche, Consultant of: Consultant for Bristol-Myers Squibb, Roche, Novartis, Medimmune, Union Chimique Belge, Speakers bureau: Speaker for Bristol-Myers Squibb and Novartis. DOI: 10.1136/annrheumdis-2020-eular.4439

\begin{tabular}{|l|l}
\hline OP0163 & 2019 UPDATE OF THE JOINT EUROPEAN LEAGUE \\
AGAINST RHEUMATISM AND EUROPEAN RENAL \\
ASSOCIATION-EUROPEAN DIALYSIS AND \\
TRANSPLANT ASSOCIATION (EULAR/ERA-EDTA) \\
RECOMMENDATIONS FOR THE MANAGEMENT OF \\
LUPUS NEPHRITIS
\end{tabular}

A. Fanouriakis ${ }^{1}$, M. Kostopoulou², K. Cheema ${ }^{3}$, H. J. Anders ${ }^{4}$, M. Aringer ${ }^{5}$ I. Bajema ${ }^{6}$, J. N. Boletis ${ }^{1}$, E. Frangou ${ }^{7}$, F. Houssiau ${ }^{8}$, J. Hollis ${ }^{9}$, A. Karras ${ }^{10}$ F. Marchiori ${ }^{11}$, S. Marks ${ }^{12}$, G. Moroni ${ }^{13}$, M. Mosca ${ }^{14}$, I. Parodis ${ }^{15}$, M. Praga ${ }^{16}$, M. Schneider ${ }^{17}$, J. S. Smolen ${ }^{18}$, V. Tesar ${ }^{19}$, M. Trachana ${ }^{20}$, R. V. Vollenhoven ${ }^{21}$ A. Voskuyl ${ }^{21}$, Y. K. O. Teng ${ }^{6}$, B. Van Leeuw ${ }^{22}$, G. Bertsias ${ }^{23}$, D. Jayne ${ }^{9}$, D. Boumpas ${ }^{1} .{ }^{1}$ University of Athens, Athens, Greece; ${ }^{2} \mathrm{G}$. Gennimatas General Hospital, Athens, Greece; ${ }^{3}$ University of Cambridge, Cambridge, Greece; ${ }^{4}$ University of Munich, Munich, Greece; ${ }^{5}$ University of Dresden, Dresden, Germany; ${ }^{6}$ University of Leiden, Leiden, Netherlands; ' Limassol General Hospital, Limassol, Greece; ${ }^{8}$ University catholique de Louvain, Brussels, Belgium; ${ }^{9}$ University of Cambridge, Cambridge, United Kingdom; ${ }^{10}$ University of Paris, Paris, France; ${ }^{11}$ Lupus Europe, Rome, Italy; ${ }^{12}$ University College London, London, United Kingdom; ${ }^{13}$ University of Milan, Milan, Italy; ${ }^{14}$ University of Pisa, Pisa, Italy; ${ }^{15}$ Karolinska University Hospital, Stockholm, Sweden; ${ }^{16}$ Complutense University, Madrid, Spain; ${ }^{17}$ University of Düsseldorf, Düsseldorf, Germany; ${ }^{18}$ University of Vienna, Vienna, Austria; ${ }^{19}$ Charles University, Prague, Czech Republic; ${ }^{20}$ University of Thessaloniki, Thessaloniki, Greece; ${ }^{21}$ Amsterdam University Medical Centers, Amsterdam, Netherlands; ${ }^{22}$ Lupus Europe, Essex, United Kingdom; ${ }^{23}$ University of Crete, Heraklion, Greece

Background: Up to $40 \%$ of systemic lupus erythematosus (SLE) patients develop kidney disease, which represents a major cause of morbidity. Objectives: To update the 2012 EULAR/ERA-EDTA recommendations for the management of lupus nephritis (LN).

Methods: We followed the EULAR standardised operating procedures for the publication of treatment recommendations. Delphi-based methodology led to 15 questions for systematic literature review (SLR), which was undertaken by three fellows. Results: The changes include recommendations for treatment targets, use of glucocorticoids and calcineurin inhibitors (CNI), and management of 